\title{
Livros didáticos e outros materiais escritos no Colégio Técnico da UFMG (1969-1997)
}

\author{
Textbooks and other written materials in Colégio Técnico-UFMG (1969-1997)
}

\author{
Kelly Maria de Campos Fornero Abreu de Lima Melillo ${ }^{1}$ \\ Maria Laura Magalhães Gomes ${ }^{2}$
}

\section{Resumo}

Este artigo aborda o uso de livros didáticos e outros materiais escritos nas práticas dos professores de Matemática do Colégio Técnico da Universidade Federal de Minas Gerais no período 1969-1997. O trabalho resulta de uma pesquisa fundamentada na metodologia da História Oral, com a realização de 16 entrevistas com antigos professores e alunos da escola. Os depoimentos dos professores minimizaram o papel dos livros em suas práticas, acentuando a sua própria produção de materiais escritos, com destaque para estudos dirigidos e instruções programadas para as aulas. Os testemunhos dos alunos se referiram à pouca frequência de aulas expositivas decorrente do uso desses materiais e em geral não enfatizaram o uso de livros. Entretanto, a análise das narrativas revelou que os livros didáticos estiveram muito presentes nas práticas desenvolvidas na escola, por serem essenciais à preparação e à realização dos estudos dirigidos.

Palavras-chave: Livros didáticos de Matemática; Estudo dirigido e instrução programada; Colégio Técnico da UFMG; História Oral.

\begin{abstract}
This article focuses on the use of textbooks and other written materials in the practices of Mathematics teachers of Colégio Técnico, Universidade Federal de Minas Gerais, from 1969 to 1997. It presents results from a research based on 16 interviews with former teachers and students according to Oral History methodology. Teachers' statements minimized the role of books in their practices, emphasizing their own production of written materials, with emphasis on guided studies and progammed instruction for classrooms. Student testimonials referred to the lack of lectures by Mathematics teachers due to the use of these materials and did not generally emphasize the use of books. However, the analysis of the narratives revealed that the textbooks were present in the practices developed in the school, because they were essential to the preparation and the accomplishment of the directed studies.
\end{abstract}

Keywords: Mathematics textbooks; Directed study and programmed instruction; Colégio Técnico- UFMG; Oral History.

\footnotetext{
Submetido em: 15/12/2018 - Aceito em: 27/03/2019 - Publicado em: 30/03/2019

${ }^{1}$ Doutora em Educação pela Universidade Federal de Minas Gerais. Professora do Setor de Matemática do Colégio Técnico da Universidade Federal de Minas Gerais, Brasil. Email: kellyfornero@yahoo.com.br.

2 Doutora em Educação pela Universidade Estadual de Campinas. Bolsista de Produtividade do CNPq. Professora do Departamento de Matemática e do Programa de Pós-Graduação em Educação da Universidade Federal de Minas Gerais, Brasil. Email: mlauramgomes@gmail.com.
} 


\section{Introdução}

DOI: https://doi.org/10.20396/zet.v27i0.8654121

No Brasil e em outros países, os livros didáticos ou manuais escolares ${ }^{3}$ vêm se mantendo, nas últimas décadas, como tema de grande interesse dos pesquisadores em Educação. Munakata (2012) acentua o grande volume de produções sobre esse tipo de impresso, afirmando que, de 1993 a 2000, registraram-se 265 títulos referentes a esse material escolar e que de 2001 a 2011 constatou-se o aparecimento de cerca de 800 trabalhos sobre a temática em eventos, periódicos acadêmicos e projetos. Na produção sobre os livros didáticos, destaca-se a grande potencialidade desse impresso para o estudo da história da cultura escolar, no papel de fonte e de objeto.

Não tem sido diferente a situação no que diz respeito à História da Educação Matemática, campo que tem acolhido um número significativo de trabalhos que envolvem os livros didáticos de Matemática (Dassie, 2012a, 2012b, 2018; Dassie e Costa, 2014; Mendes e Valente, 2017; Valente, 2010).

Não obstante a grande produção de pesquisas sobre e com manuais escolares, tem-se observado que essa produção concerne preferencialmente à análise de seu conteúdo, investindo pouco no que diz respeito às questões ligadas à recepção dos livros didáticos. Para Rocha e Somoza (2012, p. 24),

[...] a maioria das investigações permanece centrada no momento da emissão da mensagem ou do discurso presente nos livros, sem avançar sobre o momento da recepção. Assim, permanecem na penumbra os processos de decodificação, interpretação, contestação e apropriação que os alunos realizam, assim como as ações de mediação e transformação dos conteúdos originais que os educadores e as próprias instituições escolares produzem, seja de maneira intencional ou contingente.

Quanto aos livros escolares Munakata (2012), ao exemplificar fartamente a diversificação temática das investigações sobre os livros didáticos, também alerta para aquela que considera uma questão crucial: "afinal, como são efetivamente utilizados os livros didáticos na sala de aula por professores e alunos?" (p. 192). Vimos constatando a existência de algumas contribuições no sentido de pesquisar os processos de apropriação dessas obras em práticas de leitura e de ensino. Assim, Dassie (2018), valendo-se de um dos caminhos indicados por Galvão e Batista (2008), isto é, diante da impossibilidade de captar as leituras in loco e os leitores de "carne e osso", que, na maior parte das vezes, já não estão vivos ou deixaram raros vestígios de suas experiências, procurar, nos próprios textos e na materialidade do impresso, marcas indicativas que possam contribuir para a reconstrução do leitor pensado pelo autor e/ou editor no momento da produção do objeto de leitura. Dassie

\footnotetext{
${ }^{3}$ Há ainda muitas outras designações para esse impresso. Neste artigo, usaremos indiferentemente as expressões livro didático, livro-texto, manual escolar, manual didático, livro escolar, entre outras, para denominar esse tipo de publicação. Batista (1999) chama a atenção para a variabilidade e a instabilidade desse material, do ponto de vista histórico, ao considerar a heterogeneidade dos suportes dos textos, a variação dos meios de reprodução das obras escolares e de seu processo de produção. Comenta, ainda, a diversidade dos modos de encenar sua leitura e utilização.
} 
DOI: https://doi.org/10.20396/zet.v27i0.8654121

tem se dedicado a explorar prefácios, prólogos, notas ao leitor, advertências, entre outros elementos paratextuais, no intuito de interpretar as interações entre autores de livros didáticos e professores. Em particular, o autor mobiliza as notas de manuais escolares de autoria de Jácomo Stávale e Nelson Benjamin Monção como recurso para a compreensão das "relações que podem ser estabelecidas entre livros didáticos e atuação profissional do professor" (Dassie, 2018, p. 72).

Outra contribuição para o conhecimento dos usos e práticas de livros didáticos de professores de Matemática é representada por Giani (2004), que, motivada pela presença marcante dessas obras no contexto escolar, empreendeu uma investigação sobre os critérios dos docentes quanto à escolha do livro-texto, aliada à intenção de compreender as concepções de Matemática e de seu ensino e aprendizagem desvendadas por esses critérios. A pesquisa usou a metodologia da História Oral, com a realização de 10 entrevistas com professores dos anos finais do Ensino Fundamental. Em linha semelhante, podemos mencionar o trabalho de Vieira e Gomes (2014), que resultou de uma investigação centrada nos livros escolares que envolveu como colaboradores 10 professores dos anos iniciais do Ensino Fundamental da rede pública e privada de Belo Horizonte, também com a utilização da História Oral como metodologia.

Ao focalizar as práticas de ensinar-aprender Matemática no Colégio Técnico (Coltec) da Universidade Federal de Minas Gerais (UFMG), situado em Belo Horizonte, no período 1969-1997, Melillo (2018), compreendeu-as em âmbito ampliado em relação ao trabalho do professor em sala de aula, estudando, entre diversos aspectos, o currículo, a rotina, as decisões dos docentes, os materiais e recursos produzidos e utilizados por eles. A pesquisa envolveu o uso da metodologia da História Oral e colheu depoimentos de um antigo diretor, sete professores de Matemática e oito estudantes da escola no período de referência do trabalho. Com base no princípio de que a história do ensino de uma disciplina não pode ser feita sem analisar seus livros-texto e o material utilizado por docentes e discentes (Viñao, 2012), a pesquisa investiu na busca de informações referentes a esses recursos em diversas fontes, entre as quais se destacam as obtidas pelos testemunhos de professores e alunos em entrevistas. Neste artigo, visando trazer aportes aos conhecimentos sobre o uso dos manuais escolares e outros materiais escritos, concentramos a atenção sobre os resultados oferecidos pela investigação no que diz respeito a eles na Matemática presente no Coltec de 1969 a 1997. Começamos por apresentar algumas considerações acerca da metodologia da História Oral e de sua utilização na pesquisa de Melillo (2018).

\section{Considerações sobre a História Oral e os sujeitos colaboradores deste trabalho}

Dentre as estratégias para compreendermos a utilização dos livros didáticos e outros materiais escritos no passado, destacamos o emprego das fontes orais. A partir de entrevistas com professores e alunos, é possível desvelar encantamentos, desencantamentos, ansiedades, motivos e justificativas para determinadas vivências escolares e, particularmente, investigar o uso de manuais educacionais (Garnica, Fernandes \& Silva, 2011). A oralidade permite Zetetiké, Campinas, SP, v.27, 2019, p.1-16 - e019003 
DOI: https://doi.org/10.20396/zet.v27i0.8654121

construir dimensões que não encontramos em documentos de outra natureza: acontecimentos pouco esclarecidos ou nunca evocados, experiências pessoais, impressões particulares, informações não registradas na forma escrita.

A pesquisa de Melillo (2018) recorreu às fontes documentais, impressas e audiovisuais, mas privilegiou o uso da História Oral como metodologia e fundamentação teórica. Em consonância com Garnica (2015, p. 38), a autora não buscou "apenas como fazer, mas por que fazer de um determinado modo". Sendo assim, a História Oral guiou os procedimentos de constituição de fontes e a escolha dos métodos utilizados nessa investigação.

Ao empregar História Oral, o pesquisador torna-se um fazedor consciente de fontes orais. Nesse exercício, constroem-se interpretações de situações, escolhas ou experiências de sujeitos que as vivenciaram, acompanharam ou observaram.

Trata-se de ampliar o conhecimento sobre acontecimentos e conjunturas do passado por meio do estudo aprofundado de experiências e visões particulares; de procurar compreender a sociedade através do indivíduo que nela viveu; de estabelecer relações entre o geral e o particular mediante análise comparativa de diferentes testemunhos, e de tomar as formas como o passado é apreendido e interpretado por indivíduos e grupos como dado objetivo para compreender suas ações (Alberti, 2003,p. 26).

No presente trabalho, consideramos as dezesseis entrevistas realizadas por Melillo (2018). Como já foi dito, o grupo de depoentes da pesquisa em foco foi composto por oito exalunos, sete ex-professores e um ex-diretor do Colégio Técnico da UFMG. Os áudios foram gravados e transcritos posteriormente, ou seja, realizou-se a passagem do registro oral para o registro escrito, buscando manter fidelidade à gravação por meio do registro escrito de erros, barulhos e ruídos.

As transcrições foram seguidas de textualizações. Nessa etapa, retiraram-se as marcas mais fortes da oralidade e recriaram-se as informações do conteúdo transcrito, considerando a ordem cronológica dos acontecimentos narrados ou temáticas pré-definidas. Portanto, as histórias que os sujeitos contaram, suas narrativas, serviram para constituir outras narrativas nas quais se mesclaram as vozes dos entrevistados e as das pesquisadoras, autoras deste $\operatorname{artigo}^{4}$.

Vale ressaltar que as fontes oriundas dos procedimentos da História Oral, sejam as gravações em áudio, as transcrições ou as textualizações, não contam o que o sujeito fez, viu ou ouviu. Essas fontes constituem narrativas que abrigam as intenções dos colaboradores: o que queriam ou acreditavam ter feito, visto ou ouvido. Com efeito, todos esses métodos de registro da memória filtram a realidade, seja devido ao tempo decorrido, às condições socioculturais, ao espaço ou às condições do momento da entrevista. As lembranças construídas são, portanto, impregnadas de sonhos, intenções e princípios.

\footnotetext{
${ }^{4}$ As dezesseis textualizações encontram-se, na íntegra, nos apêndices do trabalho de Melillo (2018).
} 
DOI: https://doi.org/10.20396/zet.v27i0.8654121

Melillo (2018) entrevistou sete professores de Matemática, cujo período de exercício no Coltec figura após seus nomes, a seguir: Abdala Gannam (1970-1992), José Eloísio Domingos - Jed (1970-1999), Luiz Humberto Pinheiro (1970-1991), Maria do Carmo Vila (1979-1995), Francisco Bastos Gil (198?-1992)5 , Tânia Lima Ayer de Noronha (1979-2002) e Airton Carrião Machado (1992-2016).

Ao que parece, trata-se de um grupo peculiar de educadores, em virtude, especialmente, de suas condições profissionais como professores de uma universidade pública importante no cenário brasileiro. A leitura de suas narrativas possibilitou inferir que a maioria desses docentes desenvolviam práticas de ensino que iam ao encontro de discussões no âmbito educacional do período e disseminavam seus métodos em congressos e cursos de capacitação, conforme assinalou Airton ${ }^{6}$.

Desde que eu estou aqui, antes eu não sei, sempre teve alguém no setor que era ligado à Educação Matemática, ou seja, estava antenado com o que estava acontecendo. Inicialmente, era a Maria do Carmo, depois passou a ser eu. Nós sempre estivemos lendo coisas novas e tal. Com isso, ao lermos pesquisas, nos colocamos na fronteira. Dessa forma, antes de as coisas virarem moda na maioria das escolas, a gente já conhecia, já havia experimentado. Nesse sentido, a gente andava um pouco na frente, porque sempre tinha alguém aqui que estava antenado no que havia de mais moderno (Airton Carrião Machado, Entrevista, 08/03/2016).

Colaboraram, também, oito ex-estudantes, o que possibilitou um outro olhar sobre os aspectos investigados. Três deles cursaram Eletrônica no Coltec: Alberto de Figueiredo Gontijo e Adilson Assis Moreira, alunos da década de 1970, e Antônio Carlos Inácio Moreira, que integrou a primeira turma desse curso, em 1969. Quatro fizeram o curso de Química: Poliana ${ }^{7}$ e Gilberto do Vale Rodrigues, na década de 1980, e as irmãs Niriana Lara Santos Meinberg e Lilian Lara Santos, que ingressaram no Colégio nos anos de 1991 e 1996, respectivamente. Entrevistamos ainda o ex-aluno Jenner Karlisson Pimenta dos Reis, da turma de Patologia Clínica, com ingresso em 1981.

Além dos professores e ex-alunos mencionados, o primeiro diretor geral do Colégio Técnico, Gledsom Coutinho, integrou o grupo de depoentes da investigação. Gledsom enriqueceu o trabalho com nomes e informações sobre os ingleses ${ }^{8}$ que fundaram a escola, com detalhes sobre alunos e a estrutura física, sobre o relacionamento do Colégio com a Universidade e sobre possíveis interferências, no cotidiano escolar, da ditadura militar implantada no Brasil em 1964.

\footnotetext{
5 O professor não conseguiu se lembrar do seu ano de ingresso no Coltec e não conseguimos obter uma informação mais precisa - foi possível identificar apenas que ocorreu na década de 1980.

${ }^{6}$ Trechos das falas dos entrevistados serão apresentados em itálicos.

${ }^{7}$ Poliana foi a única de nossos entrevistados a não autorizar a divulgação de seu nome real.

${ }^{8}$ O Colégio Técnico, que recebeu suas primeiras turmas de alunos em 1969, foi fundado por meio de um convênio entre a UFMG e o Conselho Britânico estabelecido em 1967. Alguns professores ingleses vieram ao Brasil e permaneceram em Belo Horizonte por algum tempo, trabalhando na escola.
} 
DOI: https://doi.org/10.20396/zet.v27i0.8654121

Findadas as entrevistas, Melillo realizou a validação das narrativas que foram produzidas, concluindo os procedimentos metodológicos da História Oral. Nesse momento, cada depoente conferiu o texto e corrigiu possíveis erros e enganos, acrescentando ou suprimindo alguma informação, legitimando o trabalho realizado (Meihy \& Ribeiro, 2011). As narrativas publicadas em Melillo (2018), revisitadas neste texto, resultam da conclusão dessas validações.

\section{Livros didáticos de Matemática e outros materiais escritos na visão dos professores do Coltec}

Nos depoimentos dos docentes do Coltec, notamos uma série de menções e comentários sobre os livros didáticos nas práticas de ensino realizadas. Um dos principais aspectos evidenciados nos testemunhos desses professores diz respeito ao papel secundário, de acordo com o que expressaram, desses impressos em seu trabalho. Algumas vezes, os professores entrevistados chegaram a expor críticas ao manual escolar. Esse é o caso do relato do professor Abdala, que disse que, durante certo período, adotava livros didáticos em suas aulas no Coltec, mas percebeu que não conseguia trabalhar em conformidade estrita com qualquer das obras que havia na época em que atuou no colégio. Sua insatisfação se explicitou ao dizer que as obras disponíveis não esclareciam como eu gostaria que fosse esclarecido. Explicou: Os alunos começavam dizendo: "não entendi isso!"; "não entendi aquilo!". Aí eu fui percebendo o que eles não entendiam e o quê e o porquê eles não compreendiam; decidi fazer meu próprio material (Abdala Gannam, Entrevista, 10/03/2016).

A posição de defesa, adoção e produção de outros materiais escritos para ensinar assumida por Abdala foi partilhada por outros docentes entrevistados, que revelaram que criavam atividades e materiais para atender a variadas demandas da prática.

O professor Gil escrevia apostilas e ressaltou sua opção por elas em detrimento dos livros didáticos, ao considerá-las suficientes para o futuro profissional dos alunos: Nunca adotei livro, porque preferia as apostilas. Na minha concepção, se os alunos dessem conta das minhas apostilas, estariam feitos, podiam ser aprovados em qualquer concurso (Francisco Bastos Gil, Entrevista, 04/10/2016).

No entanto, vários dos colaboradores da pesquisa acentuaram o uso de outros materiais escritos específicos para o ensino - os estudos dirigidos e as instruções programadas, destacando que eles constituíam o núcleo da metodologia adotada na escola quanto à Matemática durante um longo tempo. Nas palavras de Tânia:

No Departamento de Matemática do Coltec, nossa metodologia de trabalho era norteada por Estudos Dirigidos e Instruções Programadas. Eu produzi materiais que atendiam a essas metodologias. Acho que, assim que entrei no Colégio, eu apresentei um estudo sobre geometria (Tânia Lima Ayer de Noronha, Entrevista, 16/03/2016).

A afirmação de um modo próprio de ensinar Matemática no Colégio Técnico, no qual um dos elementos mais fortes era a produção de materiais didáticos pelos docentes da escola, 
DOI: https://doi.org/10.20396/zet.v27i0.8654121

pareceu-nos um componente fundamental na identidade desses profissionais, como faz sobressair o seguinte trecho da narrativa de Maria do Carmo.

Cada professor queria produzir o seu. E, em alguns casos, nós compartilhávamos nossas produções. Já naquela época, todos do Departamento tentavam fazer alguma coisa diferente. Dessa forma, o jeito de dar aula do Coltec era nosso, era estabelecido pela gente (Maria do Carmo Vila, Entrevista, 04/05/2016).

Outro depoimento que ressaltou a diferenciação das práticas de ensinar Matemática no Coltec em relação a outras escolas foi dado por Jed, que acentuou a produção de material pelos professores para que os alunos trabalhassem como um componente valorizador do ensino na instituição:

Esse tipo de trabalho, em que os professores produzem material, com a proposta dos alunos fazerem, não era próprio do setor de Matemática, era uma filosofia da escola, de todos os setores.

Paralelamente, eu percebia que o ensino das outras instituições era bem tradicional. Até onde eu me lembre, ou até onde eu fiquei sabendo, as outras escolas eram tradicionais, com poucas inovações, do tipo " $2+2=4$ e vamos que vamos!”. Que eu saiba, ou tenha ouvido falar, não tenho notícias de outras escolas que fizessem um trabalho diferenciado como o nosso (Jed, Entrevista, 02/05/2016).

Em sua entrevista, Jed sublinhou que os professores do Coltec tinham aprendido com os ingleses o "fazer" e a esse aprendizado creditou a diferenciação do ensino de Matemática do colégio em relação a outras escolas:

Nós casamos com essa ideia do "fazer", do aprender fazendo. E, talvez, tenha sido esse o diferencial do nosso curso de Matemática no Coltec. Nós usávamos muito pouco o quadro negro, ele não era a nossa primeira ferramenta. Utilizávamos o quadro quando era necessário (Jed, Entrevista, 02/05/2016).

Os entrevistados apresentaram algumas descrições dos estudos dirigidos e instruções programadas, materiais muito proeminentes em suas falas. Nas explicações sobre esses recursos, mesmo deixando claro que o apoio do material produzido pelos docentes e particularmente aquele proporcionado pelos estudos dirigidos e instruções programadas era essencial nas práticas pedagógicas, os professores mostraram que os livros eram necessários. Assim, Jed disse:

Tínhamos coleções que ficavam disponíveis na biblioteca do Colégio. (...) Os Estudos Dirigidos eram elaborados a partir dessas coleções ou de livros que eram indicados para os alunos comprarem. Esses pareciam com um roteiro, uma orientação para os estudantes seguirem o livro. $O$ objetivo era ajudá-los a ler e entender os conteúdos dos livros. As Instruções Programadas, por sua vez, eram textos, com lacunas para serem preenchidas, para os alunos completarem. Havia perguntas com espaços brancos para as respostas. Em ambos, Instrução Programada e Estudo Dirigido, incluíamos exercícios (Jed, Entrevista, 02/05/2016). 
DOI: https://doi.org/10.20396/zet.v27i0.8654121

A imagem a seguir é de um estudo dirigido elaborado pela professora Tânia em 1983, no qual deveria ser utilizado o primeiro volume da coleção "Matemática Aplicada", de Trotta, Imenes \& Jakubo (1980). É fácil observar, pela leitura dos enunciados propostos, que

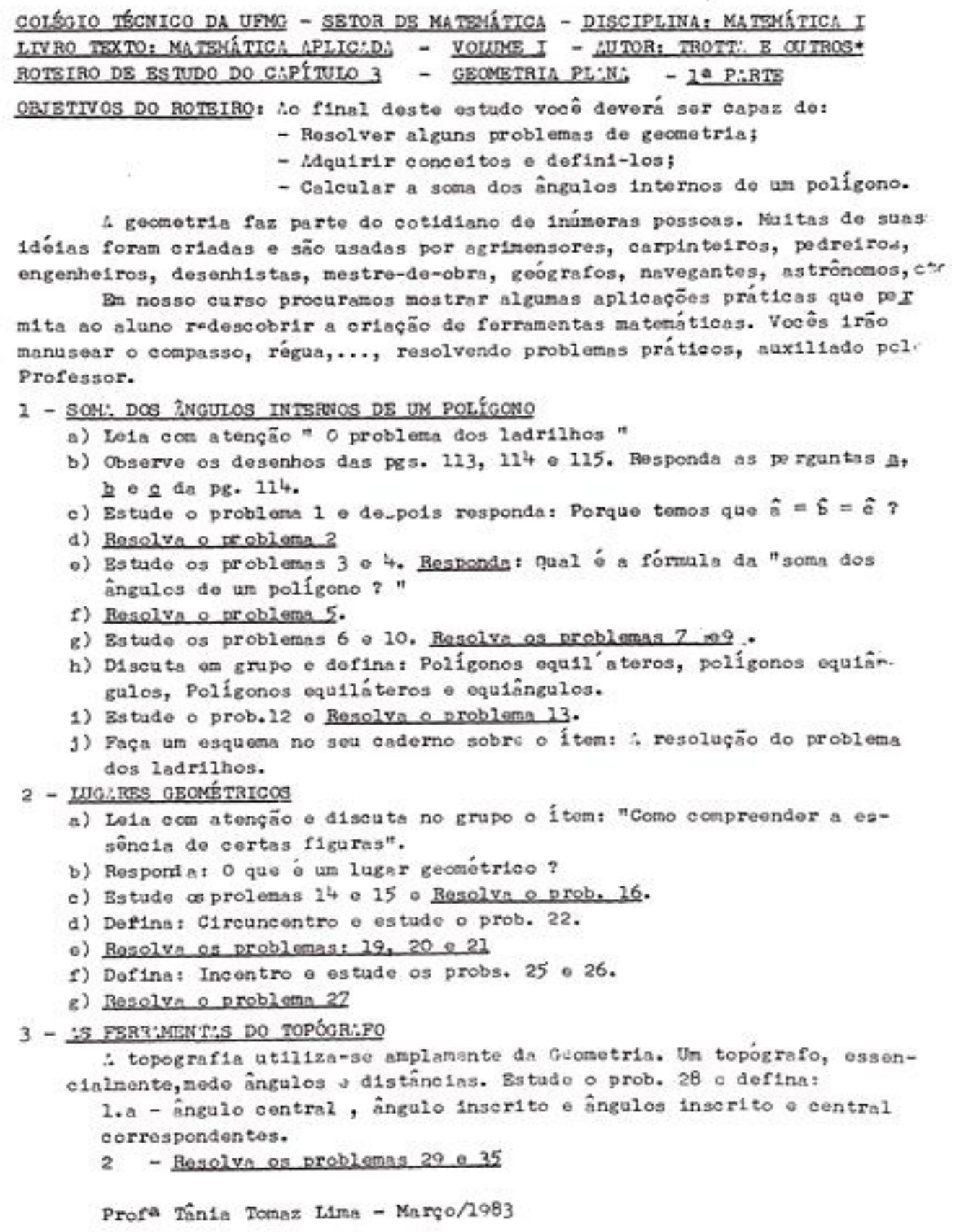

o trabalho do aluno dependia inteiramente desse livro.

Figura 1 - Estudo dirigido desenvolvido pela profa. Tânia Ayer, no Coltec, sobre geometria plana $\left(1^{\mathrm{a}}\right.$ parte $)$, em 1983. Recomenda o livro "Matemática Aplicada", volume I, de "Trota e outros" autores.

Fonte: Materiais do Setor de Matemática do Coltec. 
Também a narrativa de Abdala mostrou a necessidade de dispor de livros para os estudos dirigidos, que se baseavam neles. Contudo, os manuais não tinham o mesmo papel nas instruções programadas.

Produzi muito material para o Departamento de Matemática do Coltec. Escrevi muitas apostilas, Estudos Dirigidos e Instruções Programadas.

Vou exemplificar como fazíamos o Estudo Dirigido: primeiro o aluno é convidado a ler um texto. Depois são inseridas perguntas e exercícios do texto, cujas respostas demandam interpretação. Eu indicava muito o livro do Trotta. (...)

Na Instrução Programada, uma informação pequena é fornecida. Em seguida, trabalha-se com esse dado passo a passo. Não havia, como no Estudo Dirigido, a leitura de um texto base (Abdala Gannam, Entrevista, 10/03/2016).

Da mesma forma, Maria do Carmo salientou que o livro didático era o fundamento dos estudos dirigidos, detalhando como eram esses materiais e ressaltando seu papel como ferramenta para a compreensão do conteúdo dos livros pelos estudantes:

No Coltec, era comum fazermos uso de Estudos Dirigidos e Instruções Programadas. O Estudo Dirigido seguia um livro. (...) Como julgávamos que era difícil para os alunos, jovens, lerem e compreenderem os conteúdos dos livros, de forma independente, a gente fazia o Estudo Dirigido. Nele indicávamos as páginas para serem lidas, os exercícios a serem realizados, e incluíamos questionamentos, do tipo: "O que significa essa definição?", ou "O que significa a palavra tal?”. Então, a gente dissecava os parágrafos com perguntas e, em seguida, propúnhamos uma ou duas atividades do livro (Maria do Carmo Vila, Entrevista, 04/05/2016).

$\mathrm{Na}$ mesma parte de sua entrevista, a professora asseverou que as instruções programadas dispensavam o livro-texto:

No caso da Instrução Programada, nós trabalhávamos os conteúdos matemáticos, sem o uso de livros. No próprio material, nós incluíamos a matéria e propúnhamos perguntas relacionadas. Os alunos iam respondendo as questões, que vinham no final do capítulo, e conferindo no próprio material. Era muito complicado fazer uma Instrução Programada, porque você tinha que cuidar de cada detalhe do conteúdo, explorar cada tópico da matéria apresentada, minuciosamente (Maria do Carmo Vila, Entrevista, 04/05/2016).

Apresentamos adiante a imagem de uma instrução programada sobre Sistemas Numéricos, que evidencia a possibilidade de o estudante conferir suas respostas no próprio impresso. 
DOI: https://doi.org/10.20396/zet.v27i0.8654121

Se representarmos o conjunto dos números naturals por $\mathbb{N}$, e por $\mathbb{E}$ - conjunto dos negativos, qual das seguintes proposiçōes será cor .... Teta?

\section{$N \subset \mathbb{Z}$ quadro I 1 \\ $N=\mathbb{Z}^{*}$ Puadro 1 B \\ $N \subset \mathbb{Z}^{*}$ Quadro I C}

\section{is Sua resposta: $\mathbb{N} \subset \mathbb{Z}$}

Você está correto. 0 conjunto dos relativos ou 1nte1ros é a uñão de dois conjuntos disjuntos, 1sto é, o conjunto dos mímeros zatare 1s, $\{0, I, 2,3 . .$.$\} e o conjunto dos Intelos negatíos \{=1,-2$, $-3 . .0\}$.

- Vá para o quadro 2.

Ib Sua resposta: $\mathbb{N}=\mathbb{Z}^{\text {: }}$

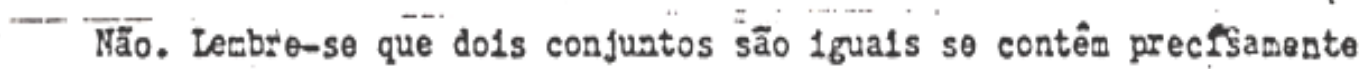
os mesmos elementos. Se representarmos o conjunto dos núperos naty

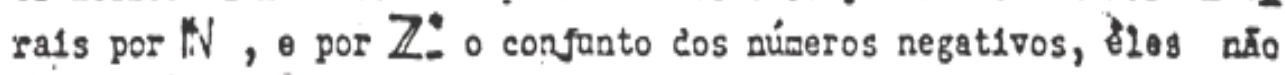
conterăo c.s mesmos elesentos. De fato, êles não tẻn elenentos comuns. Volte ao quadro. 1 e experirente de nôvo.

IC Sua resposta: $\mathbb{N} \subset \mathbb{Z}$ :

Hão. $\mathbb{N}$ é o conjunto dos números natura1s $e \mathbb{Z}$ : i o confunto dos 1ntelros negativos. $\mathbb{N} \subset \mathbb{Z}^{\prime}$ se cada elemento de $N$ pertence a $\mathbb{Z}^{*}$ in nosso caso, nenhum elemento de $\mathbb{N}$ pertence a $\mathbb{Z}^{*}$. . De rato $\mathbb{N}$ e $\mathbb{Z}:$ såo d1sjuntos. Retorne a quadro $1 \mathrm{e}$ tente asvamente.

Figura 2 - Recorte da apostila intitulada Colégio Universitário - Matemática, Volume III. Conteúdo: instrução programada sobre Sistemas Numéricos - Números Reais. Página 433. Sem data e sem autoria.

Fonte: Acervo do Laboratório de Ensino de Matemática da UFMG.

Airton, professor que ingressou no Coltec somente em 1992, muito depois dos professores que começaram sua atuação na escola usando os estudos dirigidos e instruções programadas, também os descreveu, e relatou o que observou nos estudantes durante o uso desses recursos, comentando o que ele próprio pensava a seu respeito:

Os Estudos Dirigidos e as Instruções Programadas eram propostos com muitas etapas. Vinha uma frase seguida de um espaço vazio para o aluno completar. Ou, ainda, o estudante fazia uma sequência de exemplos, repetia dez vezes um determinado exercício, depois era perguntado a ele: "O que você percebeu agora?". Eu percebia que tinha aluno 
DOI: https://doi.org/10.20396/zet.v27i0.8654121

que não tinha paciência de fazer isso. Ele já ia direto responder a pergunta, antes mesmo de resolver a sequência. Aliás, eu já tive contato com ex-alunos que me relataram que achavam aquilo muito lento. Da minha parte, eu também não compreendia. Talvez, se eu tivesse uma melhor formação a respeito, eu entendesse melhor. Mas eu achava aquilo muito devagar e os exercícios muito fáceis (Airton Carrião Machado, Entrevista, 08/03/2016).

No Coltec, o uso dos materiais produzidos pelos professores acarretou uma dinâmica específica na sala de aula, não exclusiva da Matemática, que raramente era a de uma aula expositiva, com os alunos sentados de frente para a lousa enquanto o professor explicava os assuntos. Como disse Jed, as instruções dos materiais - estudos dirigidos e instruções programadas - eram do tipo "faça aqui", "pega ali", "lê, estuda e faz":

Os alunos ficavam sentados em grupos, conforme queriam, e eu ficava ali, disponível. Sempre que precisavam, era só me chamar. O material já era preparado pensando no trabalho em grupos. Isso iniciou-se cedo; quando eu entrei no Colégio já era assim (Jed, Entrevista, 02/05/2016).

A ausência das aulas expositivas, devido à utilização preponderante dos estudos dirigidos e instruções programadas, também foi mencionada por Abdala:

Em síntese, nossa metodologia de ensino era toda calcada em estudos dirigidos. Não havia aulas expositivas: os alunos tinham atendimento individual. A exposição era realizada apenas quando percebia-se que vários alunos estavam com uma mesma dúvida (Abdala Gannam, Entrevista, 10/03/2016).

A produção dos estudos dirigidos e instruções programadas pelos professores do Colégio Técnico não ocorreu por acaso, tendo em vista que dois fatores contribuíram para ela: a formação acadêmica de alguns professores e as condições de trabalho oferecidas pela escola, integrante de uma universidade de grande porte.

O depoimento de Airton ilumina a trajetória de dois dos professores entrevistados, Maria do Carmo e Abdala, que foram alunos do programa pioneiro de mestrado interdisciplinar em Ensino de Ciências e Matemática oferecido pela Organização dos Estados Americanos (OEA), na Universidade Estadual de Campinas (Unicamp), dirigido por Ubiratan D’Ambrosio (Muniz, 2013).

De outro modo, vale salientar que os professores que atuavam no Colégio eram muito bem qualificados. Maria do Carmo, por exemplo, fez mestrado em Educação Matemática no começo dos anos 1980, naquela turma da Unicamp, pioneira na área no país, organizado pelo Ubiratan D'Ambrosio. Ela foi formada com o que tinha de mais moderno. Era o fim do Movimento da Matemática Moderna, mas era possível identificar, nas apostilas que ela produzia, muitas ideias desse movimento. Tinha ainda a influência de Piaget nas propostas elaboradas em formato de Instruções Programadas (Airton Carrião Machado, Entrevista, 08/03/2016).

O próprio Abdala destacou que havia mudado sua postura e ações como professor após ter realizado esse curso. 
DOI: https://doi.org/10.20396/zet.v27i0.8654121

Modifiquei meu comportamento didático depois do curso da Unicamp, quando tive acesso a várias propostas metodológicas. $O$ curso de mestrado era bem moderno, com participação de pessoas de diversos países. Em certo momento, veio um professor dos Estados Unidos para oferecer um curso sobre calculadora eletrônica no ensino de Matemática, por exemplo. Além dele, como já me referi anteriormente, fiz um curso com um porto-riquenho que trabalhava com audiovisuais aplicados ao ensino. Aprendi bastante coisa com ele. Ele propunha ideias e, a partir delas, eu desenvolvia materiais para o ensino de Matemática. Ele ficou na Unicamp um mês oferecendo cursos e eu "no calcanhar dele" (Abdala Gannam, Entrevista, 10/03/2016).

Se a formação dos professores favoreceu o uso dos estudos dirigidos e instruções programadas, a produção desses materiais foi propiciada pelas condições dos docentes no Colégio, já que trabalhavam em regime de dedicação exclusiva, dispondo, assim, de tempo para além das aulas, elaborar esses textos. A confecção dos materiais era também praticada por outros setores e disciplinas do Colégio e Jed, que foi diretor da escola, lembrou-se dos gastos com papel e das atividades necessárias à disponibilização dos trabalhos para uso nas aulas:

No Colégio, a gente sempre produzia muito material. Um dos maiores gastos que nós tínhamos era com papel. Não só o Departamento de Matemática, mas todos os setores. No início do ano, avisávamos aos pais: "vocês vão trazer os meninos com poucos livros debaixo dos braços, mas papel vai ter demais". Quando fui diretor, tomei conhecimento do consumo de papel, era monstruoso. Durante muito tempo, quando o material era feito à mão, à tinta, com muita mão de obra, os professores não podiam enviar o material de última hora, porque a gráfica vivia atolada de serviços. Era muito trabalhoso rodar o material no mimeógrafo. Em seguida, vieram os computadores, com seus programas que facilitaram nosso trabalho. Depois passamos a utilizar o xerox, que melhorou ainda mais (Jed, Entrevista, 02/05/2016).

Abdala deu detalhes sobre a produção específica dos escritos para as aulas de Matemática, referindo-se às condições materiais para ela, assim como Maria do Carmo.

Quanto à formatação dos textos produzidos, alguns ficavam mais bem editados, outros não. Afinal, eram todos feitos no mimeógrafo, não tínhamos computador. Fazer as figuras dava muito trabalho. Eu usava aquelas réguas de gabarito para fazer as figuras. Em alguns casos, tinha que elaborá-las à mão. A maioria dos textos foram escritos em minha máquina de datilografar. Havia um processo meio fotográfico, para a reprodução de apostilas, um negócio hoje bem antigo (Abdala Gannam, Entrevista, 10/03/2016).

Diferentemente dos dias atuais, nós tínhamos muito trabalho para produzir materiais didáticos, provas. Inicialmente, porque não tinha nem máquina de datilografar na época, nós fazíamos tudo à mão. Depois, tinha máquina, mas era muito complicado datilografar um "módulo", uma raiz quadrada, um expoente, e nós precisávamos disso. Além disso, não era comum o uso de xerox, nós utilizávamos matrizes para confecção das apostilas. Era uma matriz muito trabalhosa, em que não era possível fazer correções. Não havia, também, muito 
DOI: https://doi.org/10.20396/zet.v27i0.8654121

papel disponível. Algumas vezes, nós dobrávamos os papéis ao meio. Papel era muito caro (Maria do Carmo Vila, Entrevista, 04/05/2016).

Os antigos alunos do Coltec que colaboraram na pesquisa apresentaram, em suas narrativas, lembranças e reflexões a respeito das aulas de Matemática e do uso dos livros didáticos e outros materiais escritos nessas aulas. A essas lembranças e reflexões dedicamos a próxima seção.

\section{Práticas de ensinar-aprender Matemática nas narrativas dos alunos: aulas, professores, livros e materiais escritos}

A maior parte dos estudantes entrevistados recordou-se dos materiais produzidos pelos professores e usados nas aulas, mencionando, por vezes, um livro didático, ao qual se referiram como "o livro do Gelson Iezzi"”. Assim, Antônio Carlos disse que, em geral, os professores, ao iniciar um assunto, lançavam mão de um problema elementar que apresentavam aos alunos e em seguida solicitavam-lhes que estudassem e resolvessem problemas em grupo. Ao falar disso, relatou:

Se tivéssemos alguma dúvida, o professor estava lá na mesa. Nós íamos até ele, ou o chamávamos, e ele nos ajudava a resolver. Finalmente, ele dava uma aula, parecendo um fechamento. Eles diziam: "Olha, o que nós vimos foi isso aqui e tal, tem esses casos particulares... ". A dinâmica era maravilhosa! Eu comecei a gostar de Matemática por causa disso (Antônio Carlos Inácio Moreira, Entrevista, 23/02/2016).

Antônio Carlos lembrou-se especificamente que havia também os estudos dirigidos, em que o professor marcava as páginas do livro para a gente ler e ficava nos orientando. Outro ex-aluno, Alberto, contou que, no primeiro ano no Coltec, havia tido aulas expositivas de Matemática com o professor Napoleão ${ }^{10}$, mas a partir do segundo ano, o professor Abdala usou outra metodologia para ensinar.

Nós entrávamos na sala, pegávamos aquele livro "Matemática Moderna", me parece que era de autoria do Gelson Iezzi, sentávamos lá e estudávamos. O professor orientava: "Vocês vão estudar o capítulo tal". Lembro que todos os alunos ficavam sentados estudando, disciplinados. Eu era muito quieto, entrava mudo e saía calado. Eu queria apenas estudar. Nós íamos fazendo os exercícios sem perguntar nada, porque o Abdala era muito ríspido. Ele permanecia sentado. Como não tinha computadores na época para ele acessar a internet, pegava um livro, um jornal e ficava lendo. Algumas vezes ouvíamos: "Olha, nosso método é assim, deixar você aprender por você, estão entendendo?". No primeiro ano foi difícil para

\footnotetext{
${ }^{9}$ Gelson Iezzi, graduado em Engenharia Metalúrgica e licenciado em Matemática pela Universidade de São Paulo - USP, professor em cursos pré-vestibulares e em faculdades em São Paulo, é autor de vários livros de Matemática para o ensino fundamental, médio e superior. Não conseguimos identificar exatamente a qual dos livros de autoria de Iezzi nossos entrevistados fizeram referência. As informações sobre ele foram encontradas em: < http://www.editorasaraiva.com.br/autor/gelson-iezzi/>. Último acesso: 26 ago. 2016.

${ }^{10}$ Luiz Napoleão Moreira, já falecido à época de realização das entrevistas, atuou como docente de Matemática no Coltec de 1969 a 1976.
} 
DOI: https://doi.org/10.20396/zet.v27i0.8654121

mim, pois eu estava habituado com os métodos tradicionais da outra escola em que eu estudei, mas depois aprendi a estudar sozinho (Alberto de Figueiredo Gontijo, Entrevista, 17/11/2015).

Alberto avaliou positivamente o método de ensino do Coltec, porque, embora tenha aludido a suas dificuldades de adaptação ao colégio durante o primeiro ano, afirmou que os conhecimentos que adquiriu em Matemática foram suficientes para que ele fizesse, sem qualquer problema, o curso superior de Engenharia Eletrônica e Telecomunicações.

O antigo estudante Adilson narrou que, em sua experiência anterior ao cursar a sétima série em uma escola do interior, havia tipo uma oportunidade oferecida pela diretora na qual um grupo de estudantes estudava por conta própria, a partir de um tipo de estudo dirigido, quando se reunia com mais cinco colegas fora da sala de aula para ler um livro de Matemática com a orientação do professor. Ele percebeu a semelhança dessa prática com as aulas do Coltec e comentou:

O aluno seguia o material e o professor apenas fazia explicações complementares, pontuais. Isso pode ter gerado dificuldade para uma parcela dos alunos, mas foi uma característica, uma marca da Matemática aqui do Coltec (Adilson Assis Moreira, Entrevista, 18/11/2015).

Embora, nas falas dos alunos, seja possível notar a menção a livros, é recorrente a referência a materiais que alguns chamaram genericamente de apostilas como a base para os estudos, como assinalado por Gilberto do Vale Rodrigues, entrevistado em 07/12/2015. Alunas que frequentaram o Coltec em período mais recente, na década de 1990, as irmãs Lilian e Niriana também fizeram comentários sobre as apostilas. No trecho da narrativa de Niriana transcrito abaixo, evidencia-se uma lembrança da dinâmica das aulas de Matemática um pouco diferente da descrita pelos alunos mais antigos. Enquanto esses disseram que os professores iam raramente ao quadro para expor a matéria, a rememoração de Niriana trouxe, antes da referência à resolução de problemas pelos estudantes, as explicações preliminares dos professores.

Acho que não utilizávamos livros, pois não me lembro de ter comprado nenhum livro no Colégio. Na época a gente utilizava muita apostila, xerox, essas coisas assim..., que eram distribuídas pelos professores para todos os alunos. Alguns materiais continham um resuminho da matéria, seguidos de exercícios que eram para serem feitos no caderno ou em espaços brancos do próprio material (Lilian Lara Santos, Entrevista, 08/03/2016).

Lembro, vagamente, de alguns materiais que continham espaços para completarmos, nas apostilas de Matemática. Quanto à dinâmica das aulas, geralmente os professores explicavam a matéria no quadro e a gente resolvia problemas. Trazíamos muitos exercícios para casa, uma quantidade enorme. Depois, a gente corrigia no quadro, os alunos levantavam e iam ao quadro solucionar. Sempre tinha um que gostava mais de ir ao quadro e ia com mais frequência (Niriana Lara Santos Meinberg, Entrevista, 08/03/2016).

É interessante observar, ainda, nos comentários de dois alunos, Antônio Carlos e Poliana, que os estudos dirigidos e apostilas usados nas aulas de Matemática foram Zetetiké, Campinas, SP, v.27, 2019, p.1-16 - e019003 
DOI: https://doi.org/10.20396/zet.v27i0.8654121

descartados quando eles selecionaram o que guardar como lembrança de seu tempo no Coltec.

As apostilas de Matemática eu não guardei, porque a maioria era de estudos dirigidos, com espaços para resolver os problemas, aí eu não guardei, até sinto falta de ter feito isso (Antônio Carlos Inácio Moreira, Entrevista, 23/02/2016).

Eu tenho cadernos das outras disciplinas, mas de Matemática eu só tenho algumas folhas soltas. Possivelmente, porque eu fazia tudo nas apostilas. Também não me lembro de utilizar livros em nenhuma disciplina (Poliana, Entrevista, 18/01/2016).

\section{Presença/ausência dos livros didáticos e outros materiais escritos nas aulas de Matemática do Coltec: o que podemos dizer?}

As narrativas de professores e ex-alunos do Coltec puseram em relevo o papel de materiais escritos, denominados apostilas, de maneira geral, ou identificados especificamente, no caso dos estudos dirigidos e instruções programadas, nas práticas de ensinar-aprender Matemática na escola. Isso parece indicar que essas práticas, pelo menos nas décadas de 1970 e 1980, não eram centradas nos livros escolares, e sim nos recursos didáticos produzidos pelos docentes, em especial nos estudos dirigidos e nas instruções programadas. Nas entrevistas, sobretudo dos professores, percebemos uma tendência a ocultar o uso dos livros didáticos. A fala da professora Maria do Carmo reforçou, inclusive, sua ausência: nós trabalhávamos os conteúdos matemáticos, sem o uso de livros (Maria do Carmo Vila, Entrevista, 04/05/2016). Jed minimizou o papel dos livros ao dizer:

Nem tão pouco privilegiávamos os livros didáticos. Nós até tentamos utilizar o livro do Gelson Iezzi, que era considerada uma boa coleção. Mas, rapidamente, vimos que não daria certo, pois, na nossa concepção, eles são preparados para professores. Quando os alunos leem, não entendem. Por outro lado, eles são úteis para os estudantes fazerem exercícios ou realizarem consultas (Jed, Entrevista, 02/05/2016).

Em contraposição a destacar o papel dos manuais escolares de Matemática em suas aulas, os discursos dos docentes, como observamos, enfatizaram seu empenho na produção do próprio material como uma atividade diferenciadora de suas práticas em relação a outras escolas. Entretanto, por outra ótica, podemos asseverar que os livros didáticos estiveram muito presentes na sala de aula de Matemática do Coltec. Isso porque, além de os estudos dirigidos os requererem de forma indispensável e os próprios professores fazerem referência a alguns manuais específicos, como aquele que designaram como "o livro do Gelson Iezzi" e a coleção de Trota, Imenes \& Jakubo (1980), os livros constituíram referências na própria preparação dos materiais escritos pelos docentes.

Os alunos também fizeram referência ao uso dos livros em seus estudos, tanto na sala de aula quanto em bibliotecas, ainda que suas falas tenham acentuado mais a utilização das apostilas e dos estudos dirigidos. As entrevistas dos estudantes salientaram o método de ensino dos professores ao fazer uso desse material, do qual decorria baixa frequência de aulas expositivas. Embora alguns tenham dito que estranharam essas práticas ao ingressar na Zetetiké, Campinas, SP, v.27, 2019, p.1-16 - e019003

ISSN 2176-1744 
DOI: https://doi.org/10.20396/zet.v27i0.8654121

escola, em geral reconheceram que elas contribuíram para sua maior autonomia e não acarretaram prejuízos em sua formação.

É preciso ressaltar que, a partir do final dos anos 1960, precisamente nos primeiros anos de funcionamento do Coltec, uma tendência pedagógica de repercussão significativa no Brasil foi o tecnicismo. No ensino de Matemática, a tendência tecnicista penetrava as discussões metodológicas e as práticas dos professores, atribuindo uma organização racional ao ensino, que diminuía as interferências subjetivas que poderiam alterar o rendimento dos procedimentos (Saviani, 2007). Iniciou-se, então, a propagação de propostas pedagógicas tais como a instrução programada e o estudo dirigido. Maria do Carmo, ao ser indagada sobre a origem dessas metodologias de ensino, comentou:

Durante um certo período, o uso dessas propostas foi difundido na Universidade, onde eram justificadas e fundamentadas por teorias. Em cada época havia uma prática sendo incentivada, como acontece atualmente. Nessa época, veio a onda da instrução programada e do estudo dirigido (Maria do Carmo Vila, Entrevista, 04/05/2016).

Existem aparentes contradições no que se refere aos comentários de alunos e professores a respeito da presença/ausência dos livros didáticos e outros materiais escritos no ensino de Matemática no Coltec, uma vez que eles surgem ou desaparecem conforme o momento da entrevista e o colaborador ou colaboradora. O uso da História Oral inclui, necessariamente, tecer considerações sobre a memória e a produção das narrativas nas entrevistas. É preciso considerar que a memória filtra, reordena, omite e recria, dependendo do tempo e das circunstâncias em que é solicitada e que as narrativas são construídas do ponto de vista de interesses concretos e específicos. Também depende do intérprete a atribuição de significados ao que é narrado. Como autoras deste artigo, acreditamos que as análises aqui apresentadas tenham contribuído para iluminar o papel desempenhado pelos livros e outros materiais escritos na prática pedagógica das aulas de Matemática do Colégio Técnico da UFMG durante o período da investigação que empreendemos.

\section{Referências}

Alberti, V. (2003). Narrativas na história oral. Anais eletrônicos do $22^{\circ}$ Simpósio Nacional de História (pp. 1-10). João Pessoa: Associação Nacional de História. Retirado em 27 de novembro, 2018, de:

http://bibliotecadigital.fgv.br/dspace/bitstream/handle/10438/6705/1346.pdf?sequence=1 \&isAllowed=y.

Batista, A. A. G. (1999). Um objeto variável e instável: textos, impressos e livros didáticos. In M. Abreu (Org.). Leitura, História e História da Leitura (pp. 529-575). Campinas: Mercado de Letras; Associação de Leitura do Brasil/ São Paulo: Fapesp.

Dassie, B. A. (2012a). A Comissão Nacional do Livro Didático após 1945 e os livros de matemática aprovados para uso no ensino secundário. Revista HISTEDBR On-line, 47, 88-107.

Dassie, B. A. (2012b). Da fragmentação à fusão: os primeiros livros didáticos no Brasil denominados de matemática. Perspectivas da Educação Matemática, 5, 7-27. 
DOI: https://doi.org/10.20396/zet.v27i0.8654121

Dassie, B. A. (2018). Analisar livros didáticos: trajetos e caminhos percorridos. Revista de História da Educação Matemática. 4, 59-74.

Dassie, B. A. \& Costa, D. A. da (2014). Livros didáticos como fonte: o que dizem as pesquisas apresentadas no I ENAPHEM. In W. R. Valente (Org.) História da Educação Matemática no Brasil: problemáticas de pesquisa, fontes, referências teóricometodológicas e histórias elaboradas (pp. 200-209). São Paulo: Livraria Editora da Física.

Galvão, A. M. O. \& Batista, A. A. G. (2008). Manuais escolares e pesquisa em história. In Veiga, C.G.; Fonseca, T.N.L (Orgs.) História e historiografia da educação no Brasil (pp. 161-188). Belo Horizonte: Autêntica.

Garnica, A. V. M. (2015). História oral em educação matemática: um panorama sobre pressupostos e exercícios de pesquisa. História Oral, 18(2), 35-53.

Garnica, A. V. M., Fernandes, D. N. \& Silva, H. da. (2011). Entre a amnésia e a vontade de nada esquecer: notas sobre regimes de historicidade e história Oral. Boletim de Educação Matemática (Bolema), 25(41), 213-250.

Giani, L. M. C. de C. (2004). Concepções de professores de Matemática: considerações à luz do processo de escolha de livros-texto. Dissertação de Mestrado em Educação para a Ciência. Bauru: Universidade Estadual Paulista "Júlio de Mesquita Filho".

Melillo, K. M. de C. F. A. de L. (2018). História de práticas de ensinar-aprender Matemática no Colégio Técnico da UFMG-Coltec (1969-1997). Tese de Doutorado em Educação. Belo Horizonte: Universidade Federal de Minas Gerais.

Mendes, I. A., \& Valente, W. R. (Orgs.) (2017). A matemática dos manuais escolares - curso primário, 1890-1970. São Paulo: Editora Livraria da Física.

Meihy, J. C. S. B. \& Ribeiro, S. L. S. (2011). Guia prático de história oral: para empresas, universidades, comunidades, famílias. São Paulo: Contexto.

Munakata, K. (2012). O livro didático: alguns temas de pesquisa. Revista Brasileira de História da Educação, 12, 179-197.

Muniz, N.C. (2013). Relatos de memórias: a trajetória histórica de 25 anos da Sociedade Brasileira de Educação Matemática (1988-2013). São Paulo: Editora Livraria da Física.

Pires Júnior, W. J. (2017). A Educação Matemática e a produção de livros didáticos: entrevista com o educador matemático Luiz Márcio Imenes. Revista de Investigação e Divulgação em Educação Matemática, 1(1), 96-118.

Rocha, H. H. P., \& Somoza, M. (2012). Apresentação do dossiê Manuais escolares: múltiplas facetas de um objeto cultural. Pro-Posições, 23(3), 21-31.

Saviani, D. (2007). História das ideias pedagógicas no Brasil. Campinas: Autores Associados.

Trotta, F., Imenes, L. M. P., \& Jakubovic, J. (1980). Matemática Aplicada. São Paulo: Moderna.

Valente, W. R. (2010). Programas e livros didáticos modernos para o ensino de matemática no Brasil: de Euclides Roxo a Osvaldo Sangiorgi. In W. R. Valente \& J. M. Matos (Orgs.). A reforma da Matemática Moderna em contextos ibero-americanos (pp. 77-102). Lisboa: UIED/FCT/UNL. 
DOI: https://doi.org/10.20396/zet.v27i0.8654121

Vieira, G. M. \& Gomes, M. L. M. (2014). Livros didáticos e formação de professores que ensinam Matemática nos anos iniciais do Ensino Fundamental. Educar em Revista, 54, 257-273.

Vinão, A. (2012). Historia de las disciplinas, profesionalización docente y formación de professores: el caso español. Pro-Posições, 23(3), 103-118. 